\title{
Evaluation of Pre-hydrated Collagenated Cortico- Cancellous Granules (Mp3®) in Augmentation of the Maxillary Sinus (Preliminary Study)
}

\author{
Samer Al Noami*, Khairy Elmosy, and Niveen Askar \\ Department of Oral \& Maxillofacial Surgery, Faculty of Oral \& Dental Medicine, Cairo University, Cairo, Egypt
}

Received: September 25, 2014; Accepted: October 23, 2014; Published: November 07, 2014

*Corresponding author: Samer Al Noami, Department of Oral \& Maxillofacial Surgery, Faculty of Oral \& Dental Medicine, Cairo University, Cairo, Egypt, Tel: +2-0111-37-23-067; E-mail: sameralnoami@yahoo.com

\begin{abstract}
Background: Bone substitutes, such as allografts, xenografts, and alloplasts, have been proposed in several augmentation procedures.

Purpose: The aim of the present study was to evaluate radiographically and histologically the pre-hydrated collagenated cortico-cancellous granules in maxillary sinus augmentation.

Materials and Methods: This study conducted on eight sinuses with residual bone height less than five mm using lateral approach technique specimens, retrieved after 6 months from augmented sinuses. The specimens processed to be observed under light microscopy. Radiographic measurements presented as means one standard deviation of bone height in millimeter and density of the newly formed bone in $\mathrm{Hu}$.

Results: Most of the particles were surrounded by newly formed bone with large osteocyte lacunae. Some slides showed marrow spaces and residual graft material reveals the beginning of new bone formation.

Conclusion: The present results show that pre-hydrated collagenated cortico-cancellous granules is a biocompatible, osteo-conductive biomaterial that can be used for maxillary sinus augmentation procedures without interfering with the normal reparative bone processes.
\end{abstract}

Keywords: Sinus Augmentation; Xenografts; Bone Regeneration; Porcine Bone-derived Biomaterial

\section{Introduction}

Autogenous bone has been reported to be the golden standard in bone regeneration procedures because it contains viable osteoblasts, organic and inorganic matrices, and biological modifiers [1]. However, the use of autogenous bone has several disadvantages, that is, a limited availability, a tendency to partially reabsorb, the need for an additional surgery, and the increased morbidity. Bone substitutes, such as allografts, xenografts and alloplasts, have been proposed in several augmentation procedures [1,2]. Maxillary sinus augmentation procedures have been used to obtain a sufficient volume of bone to allow implant placement. Different biomaterials have been used for this procedure, but there are still differences about which graft material is the most suitable. Most bone substitutes are believed to be osteo-conductive, serving as scaffold for bone formation [3-11]. Recent systematic reviews of the literature have shown a higher implant survival/success rate using xenografts as compared to autogenous bone [12-14].

$\mathrm{Mp}^{\circledR}{ }^{\circledR}$ (Tecnoss, Italy) is a heterologous origin biomaterial made of $600-1000 \mu \mathrm{m}$ or $1000-2000 \mu \mathrm{m}$ pre-hydrated collagenated cortico-cancellous granules, properly mixed with OsteoBiol ${ }^{\circledR} \mathrm{Gel}$ 0. Thus, it is possible both skipping the hydration phase and decreasing the risk of accidental exposure of material to pathogens during manipulation and grafting phases; furthermore, the syringe is flexible and ideal to simplify grafting in the receiving site. The granules are endowed with characteristics very similar to human mineral bone, [15] and can be used as an alternative to autologous bone.

Their natural micro-porous consistency facilitates new bone tissue formation in defect sites and accelerates the regeneration process.

Gradually it preserves the original graft shape and volume (osteo-conductive property) [16]. Moreover, due to its collagen content, the product facilitates blood clotting and the subsequent invasion of repairing and regenerative cells.

Therefore, the purpose of the present study was to evaluate radiographically and histologicallythe pre-hydrated collagenated cortico-cancellous granules in augmentation of the maxillary sinus.

\section{Patients and Methods}

The study involved eight sinus augmentation procedures using delayed implant placement protocols.

\section{Inclusion and exclusion criteria}

Six patients(four females and four males), with age ranges from 29-62 years with a bone height (residual height between 3 and $5 \mathrm{~mm}$ ) which requires a maxillary sinus augmentation 
procedure to place dental implants were eligible for this study Patients were reported as healthy and there was no requirement for routine medication.

This study was drawn up according to Declaration of Helsinki for experimentation on human subjects. Possible complications of surgical therapy treated following the standard protocols of dental management.

Adigital orthopantomographic radiograph with 1:1 magnification and a Cone Beam Computer Tomography (CBCT) scan of the maxilla were taken preoperatively for each patient. Antral spaces were evaluated at $1 \mathrm{~mm}$ serial sections. In these patients, CBCT scans showed residual bone in the lateralposterior segments of the edentulous maxilla below the floor of the auxiliary sinus ranged between $3 \mathrm{~mm}$ and at least $5 \mathrm{~mm}$ of height. Furthermore, average residual bone width had to be at least $6 \mathrm{~mm}$ as measured by the CT scans.

\section{Treatment Timetable}

Premedication followed the protocol suggested by Misch and Moore [17]. That is, dexamethasone $8 \mathrm{mg}$ preoperatively, $6 \mathrm{mg}$ after 24 hours, and $3 \mathrm{mg}$ after 48 hours, as anti-inflammatory drug. Systemic antibiotics, amoxicillin, were also administered 1 hour preoperatively ( $2 \mathrm{~g}$ ) and $500 \mathrm{mg}$ (Quarter in die) for 1 week. As an analgesic agent, Etodolac $600 \mathrm{mg}$ initial dose, and 200-400 mg as needed, was also prescribed.

All the patients were treated with the same surgical technique consisting of sinus floor augmentation via lateral approach [18].

Once the sinus membranes were elevated to obtain the necessary volume for bone grafting, all the maxillarysinuses were grafted using 100\% cortico-cancellousporcine bone particles (MP3 ${ }^{\circledR}$, Tecnoss, Coazze, Italy).

The bony sinus windows were covered with a re-absorbable collagen membrane (Evolution ${ }^{\circledR}$, Tecnoss, Coazze, Italy). The mucoperiosteal flaps were sutured using vertical-interrupted mattress sutures.

After 6 months, a biopsy was carried out. Cylindrical bone samples were harvested with a $2.5 \mathrm{~mm}$-internal diameter trephine exactly at the planned location of the dental implant in a vertical direction through the crestal incision to take a core biopsy containing both natural and the newly formed bone and sent to histological examination, then the implant placement completed as planned.

\section{Specimen processing and analyses}

Core biopsy specimens fixed at 10\% naturally buffered formalin, decalcified in formic acid (10\%) that renewed frequently until we ensured adequate decalcification reached by the end of the 48 hours. Then specimens embedded longitudinally into paraffin blocks and oriented in a standardized way for labeling and differentiating the newly formed bone end of the native bone.

Specimens were cut into longitudinal sections using a manual rotary microtome, and stained with Mayer's hematoxylin and eosin for histological analysis under light microscope with magnification of 20X. Representative slide samples were recorded and digitized. The slides evaluated blindly away from data and orientation for the presence of cortical and/or trabecular bone, thickness of osseous trabeculae, and the presence of lamellar and woven bone, the amount of osteoblasts and osteoclasts found the presence of fibrosis and vasculature of marrow spaces and evidence of mononuclear cell or mixed inflammatory cell infiltration.

This accomplished by using a subjective histological scoring system, which typically involves the assignment of a categorical grade according to the percentage of the tissue that is estimated visually by bone histology experienced observer to represent the quality of the newly formed bone under higher magnification (200X). It is a semi quantitative and subjected to inter- and/or intra- observer variability.

\section{Radiographic Evaluation}

\section{Patient positioning}

Standardization during imaging achieved through adjusting the patient positioning lightin the cone beam machine as follows:

The seat height adjusted to position the Region of Interest (ROI) vertically within the Field of View (FOV), and the upper light beam indicated the top of the FOV and the lower light beam indicated the bottom of the FOV.

The sagittal light (vertical front light) positioned in the center of the FOV from sagittal direction so that it is in the center of the ROI.

The lateral light (vertical side light) positioned in the center of the FOV in the lateral direction so that it is in the center of the ROI.

The patient instructed not to move during the duration of exposure, which performed at eight $\mathrm{mA}, 85 \mathrm{KV}$ and at a field of view. The image reconstruction performed using special software' and the obtained data subjected to statistical analysis.

On the second day and at 6 months postoperatively; Cone Beam Computed Tomography (СВCT) was performed on the operated side to ensure the proper graft position inside the sinus cavity, evaluate the density of the newly formed bone inside the sinus cavity, and bone height evaluation at the sub-sinus area. Natural bone height measured on immediate postoperative CBCT. Intraoral radiograph (IOR) and profile were the tools in this cone beam C.T software that we used to diagnose and record the bone height \& density.

Data analyses: Paired t-test is used to compare between mean bone height and density measurements through different periods Data presented as mean and Standard Deviation (SD) values.

The significance level was set at $p \leq 0.05$. Statistical analysis performed with IBM ${ }^{\circledR}$ SPSS $^{\circledR}$ Statistics Version 20 for Windows. 


\section{Results}

\section{Clinical observations}

All patients were operated successfully. There were no complications, except one case; with delay in the wound healing and a loss of some of the graft material. No postoperative complications presented at the time of the implant surgeries.

\section{Radiographical results}

On second day postoperative CBCT, all radiographs revealed proper position and increase in both bone height due to presence of the graft material ( $9.1 \mathrm{~mm}$ average) \&density of the grafted material (494.6 Hu average) (Figures 1\&2).

On six months postoperative CBCT, there was increase in the mean bone height ( $9.4 \mathrm{~mm}$ average) and bone density with the presence of bone deposition (666.3 Hu average). This appeared as increased radio-opacity above the subsinus bone (Figures $3 \& 4)$, except one case showed that a decrease in bone height \& density six months postoperatively (Figures 5-7).

Bone height: Second day post-operative, there was a non-statistically significant increase in mean bone height in comparison and preoperative phase.

From second day post-operative period to 6 months, there was a statistically significant increase in mean bone height.

Through the whole study period (Pre-operative to 6 months), there was a statistically significant increase in mean bone height (Table 1).

Bone density: Through the whole study period (second day postoperative to 6 months), there was a statistically significant increase in mean bone density and the newly formed bone later on.

\section{Histological results}

Under light microscope, all the histological samples of core biopsy showed areas of lacunae containing viable osteocytes. Other areas showed irregular woven bone trabecules formation surrounded by a loosely arranged and disorganized connective tissue stroma, with areas of hyalinization, and condensation of collagen fibers around areas of dystrophic calcification with granular pattern between bone tissues (Figure 8).

One of the slides showed infiltration of the connective tissue stroma with some chronic inflammatory cells as neutrophils around areas of hemorrhage (Figure 9), another showed some reversal lines denoting bone resorption followed by bone formation surrounded by disorganized connective tissue stroma (Figure 10).

At this stage (six months), some remnants of the graft material was seen, while the collagen membrane was completely resorbed.

\section{Discussion}

Maxillary sinus augmentation surgical techniques as well as osteoconductive potential of various bone substitutes have greatly evolved over the last few years, allowing predictable placement of dental implants in the regenerated maxillary premolar and molar areas.

Although the use of autogenous bone remains "the golden standard," other various bone substitutes have greatly evolved over the last few years in order to perform a predictable regeneration of maxillary posterior area with low morbidity for the patients [19].

The current study has taken under examination pre-hydrated corticocancellous porcine bone to evaluate the osteoconductive properties and the re-absorption rate after maxillary sinus

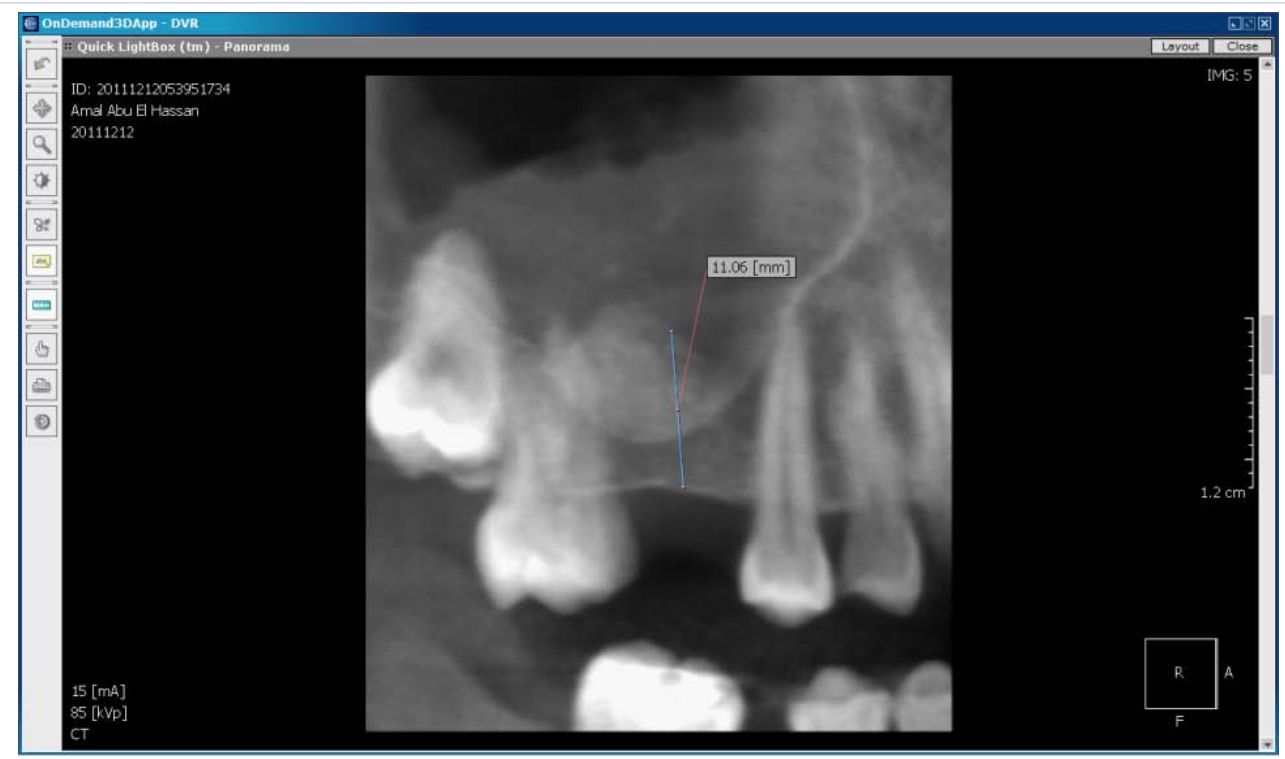

Figure 1: (Left) A photoradiograph of immediate postoperative CBCT showing increase in bone height due to presence of graft material. 


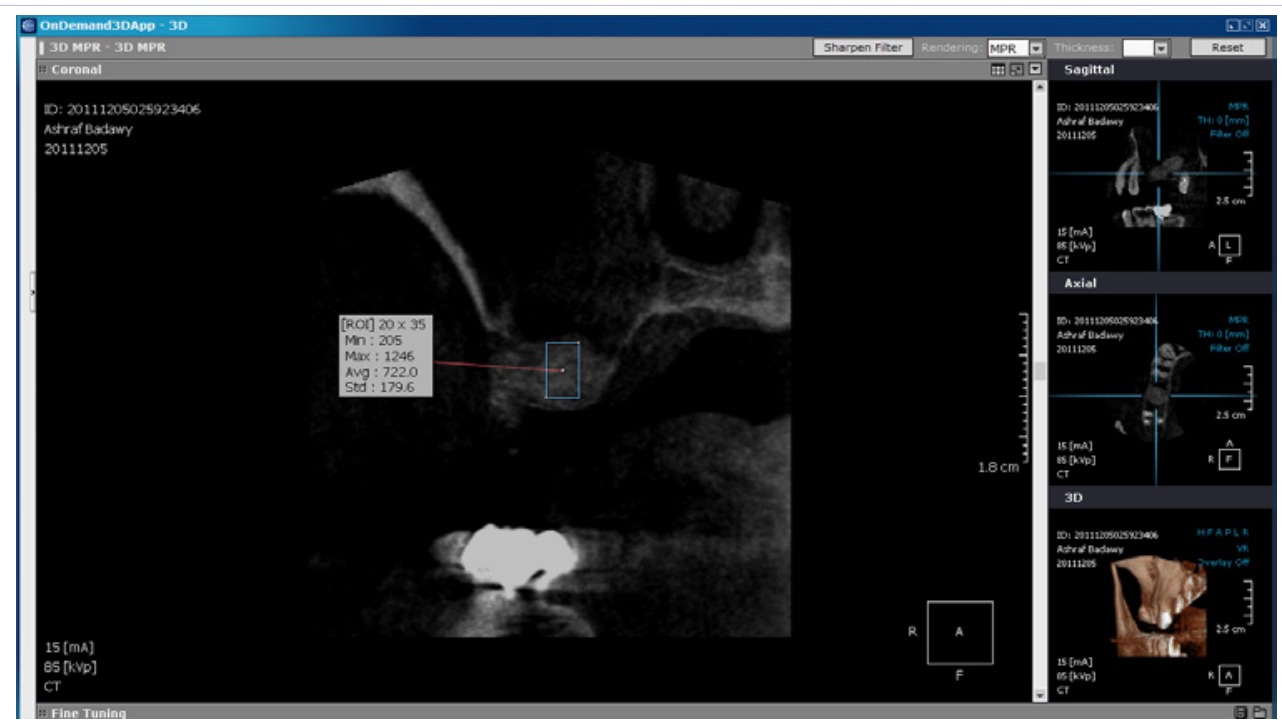

Figure 2: (Right) A photoradiograph of second-day postoperative CBCT showing the bone density.

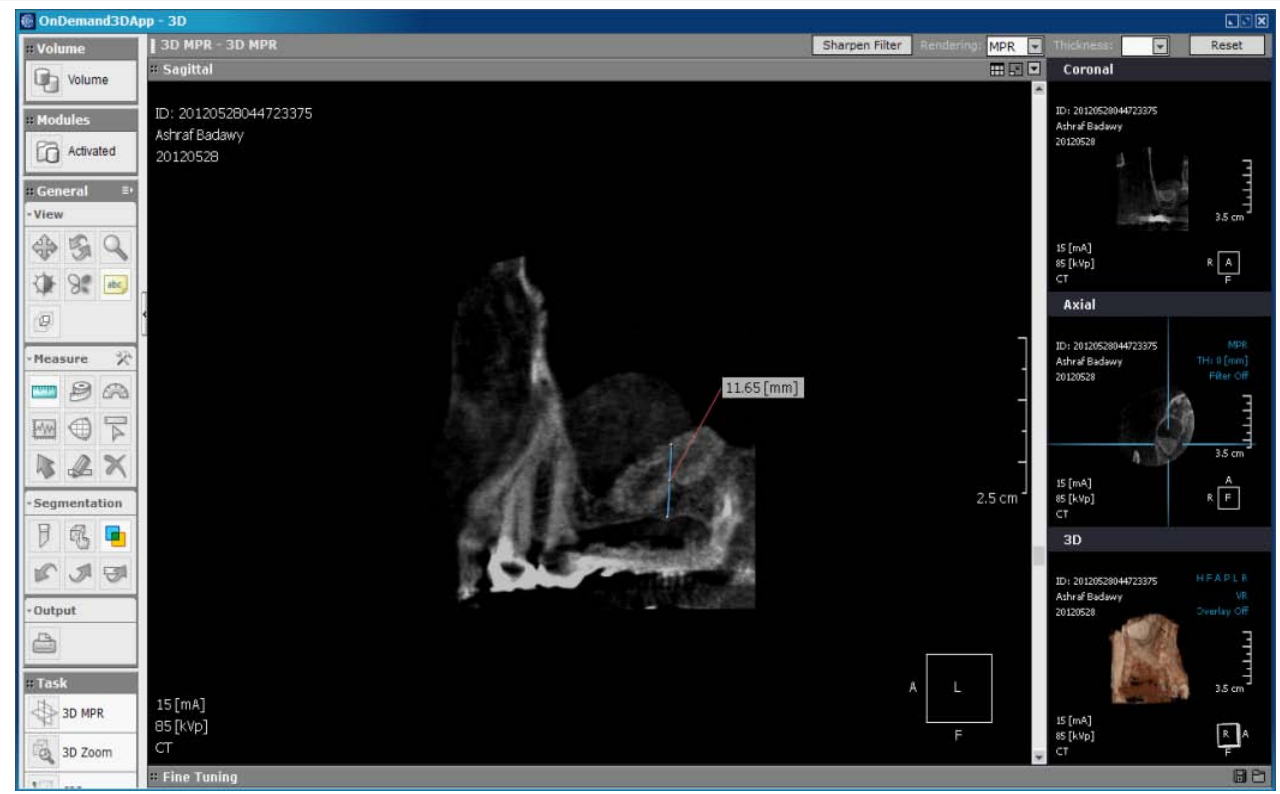

Figure 3: A photoradiograph of six months postoperative CBCT showing increase in bone height six months postoperatively.

augmentation in eight patients.

In this study the sinus floor elevation and antral augmentation by the grafting material done first, then the core biopsy and implant placement performed six months later due to the presence of less than five $\mathrm{mm}$ of bone between the crest of the ridge and the floor of the maxillary sinus, which cannot give primary stability to the implant [20].

At second day postoperative CBCT, it was found a significant increase in the relative density and bone height due to the radio opacity of the grafting material. At six months postoperatively, the radiographic result showed significant increase in the bone density and bone height due to more deposition \& calcification of the newly formed bone. These radiographic results give an idea about the rapid resorption process of the selected graft and allow newly formed bone to be completely mature before complete resorption of the graft.

All the patients scheduled in for this study showed a residual ridge height within 5 and $3 \mathrm{~mm}$; this was considered be an important clinical because the residual ridge height might be a variable to evaluate the final outcome of the procedures [21]. Therefore, in this study all patients with similar residual ridge height were treated with an identical surgical protocol. Six months after augmentation, the bone core specimens harvested vertically from the alveolar ridge where native bone is present. This is of paramount importance, since the histological results 


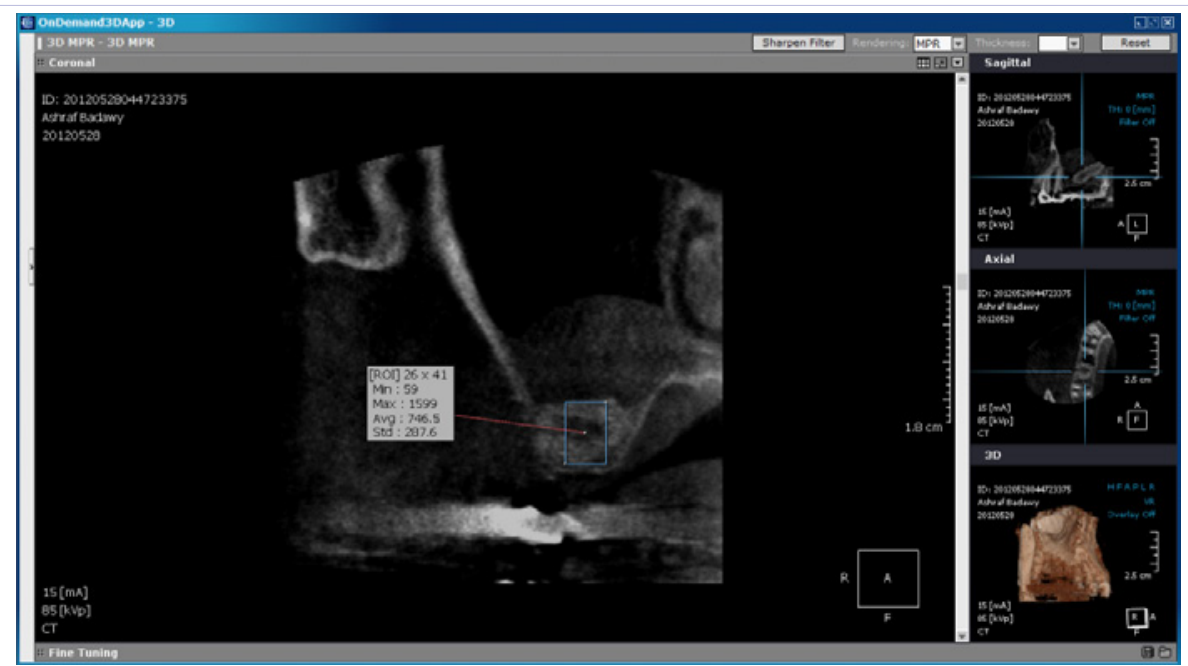

Figure 4: A photoradiograph of six months postoperative CBCT showing increase in bone density due to presence of the newly formed bone.

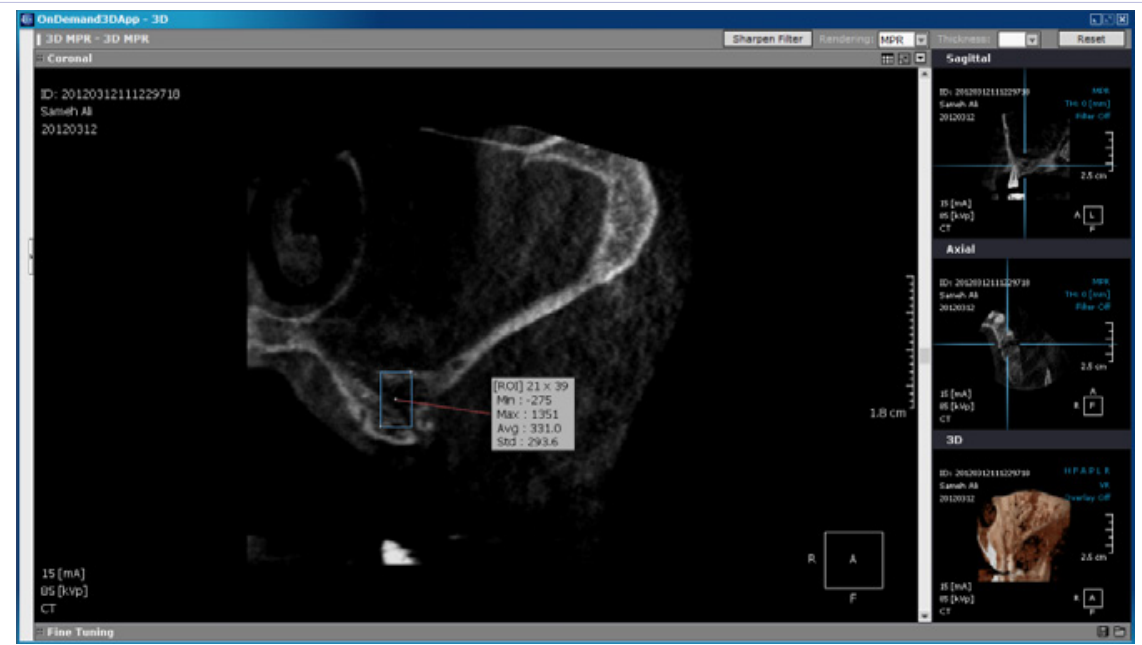

Figure 5: A photoradiograph of six months СBCT of one of the cases showing decrease in bone density of the grafted material.

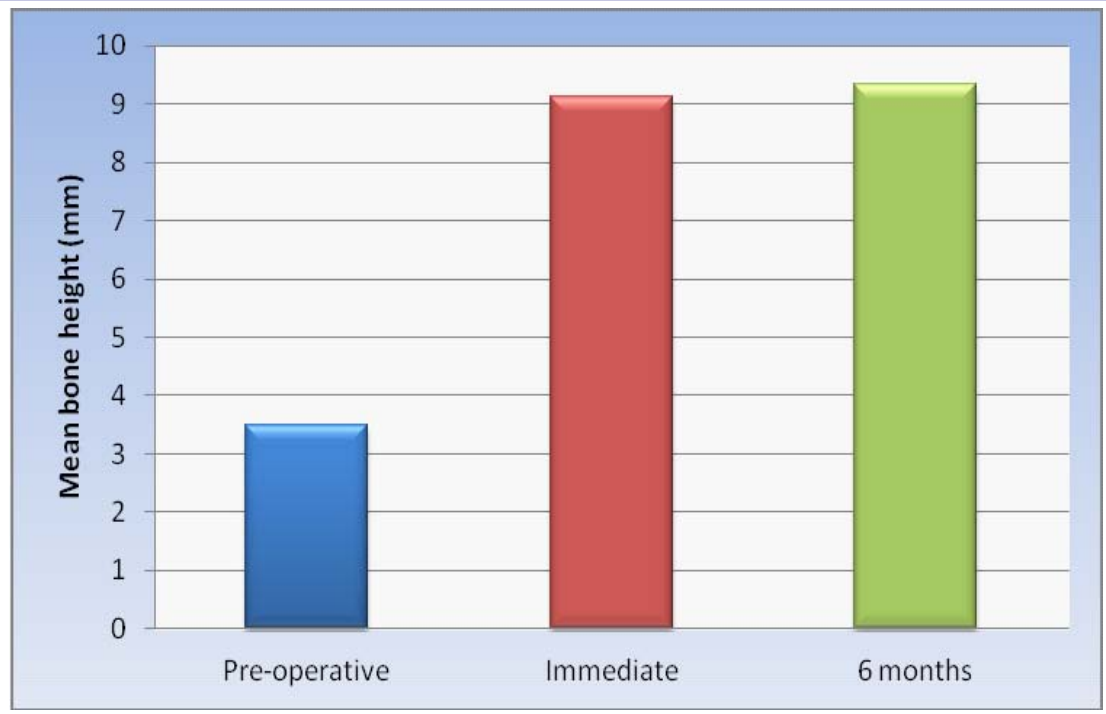

Figure 6: (Left) Bar chart representing comparison between bone heights measurements at different periods.

Citation: Noami SA, Elmosy K, Askar N (2014) Evaluation of Pre-hydrated Collagenated Cortico-Cancellous Granules (Mp3®) in Augmentation of the Maxillary Sinus (Preliminary Study). J Dent Oral Disord Ther 2(3): 1-8. 


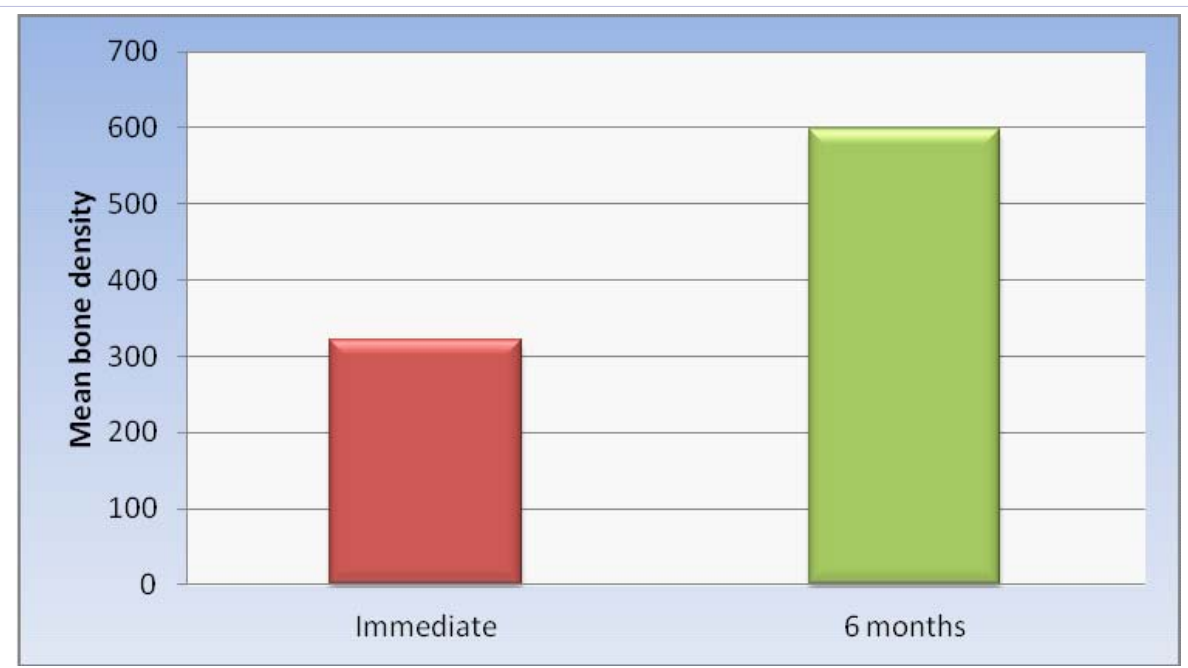

Figure 7: (Right) Bar chart representing comparison between bone density measurements at the two periods.

Table 1: Bone Height. The mean, Standard Deviation (SD) values and results of paired $t$-test for comparison between bone height measurements at the three periods.

\begin{tabular}{|c|c|c|c|c|c|c|}
\hline Time & Mean & SD & Period comparison & $\begin{array}{c}\text { Mean difference } \\
\text { (Bone gain) }\end{array}$ & Bone gain \% & $\boldsymbol{p}$ value \\
\hline Pre-operative & 3.48 & 0.99 & Pre-operative - Immediate & 5.65 & $188 \%$ & $<0.001^{*}$ \\
\hline Immediate & 9.13 & 1.46 & Immediate - 6 months & 0.20 & $2.9 \%$ & 0.456 \\
\hline 6 months & 9.33 & 1.17 & Pre-operative - 6 months & 5.85 & $194.9 \%$ & $<0.001^{*}$ \\
\hline
\end{tabular}

*Significant at $p \leq 0.05$

Table 2: Bone Density. The mean, Standard Deviation (SD) values and results of paired t-test for comparison between bone density measurements at the two periods.

\begin{tabular}{|c|c|c|c|c|c|c|}
\hline Time & Mean & SD & Period comparison & $\begin{array}{c}\text { Mean difference (Increase in } \\
\text { density) }\end{array}$ & \% Increase & $\boldsymbol{p}$ - value \\
\hline Immediate & 321.9 & 141.2 & Immediate -6 months & 276 & $96.8 \%$ & $0.001^{*}$ \\
\hline 6 months & 597.9 & 222.2 & & 276 \\
\hline
\end{tabular}

*Significant at $p \leq 0.05$

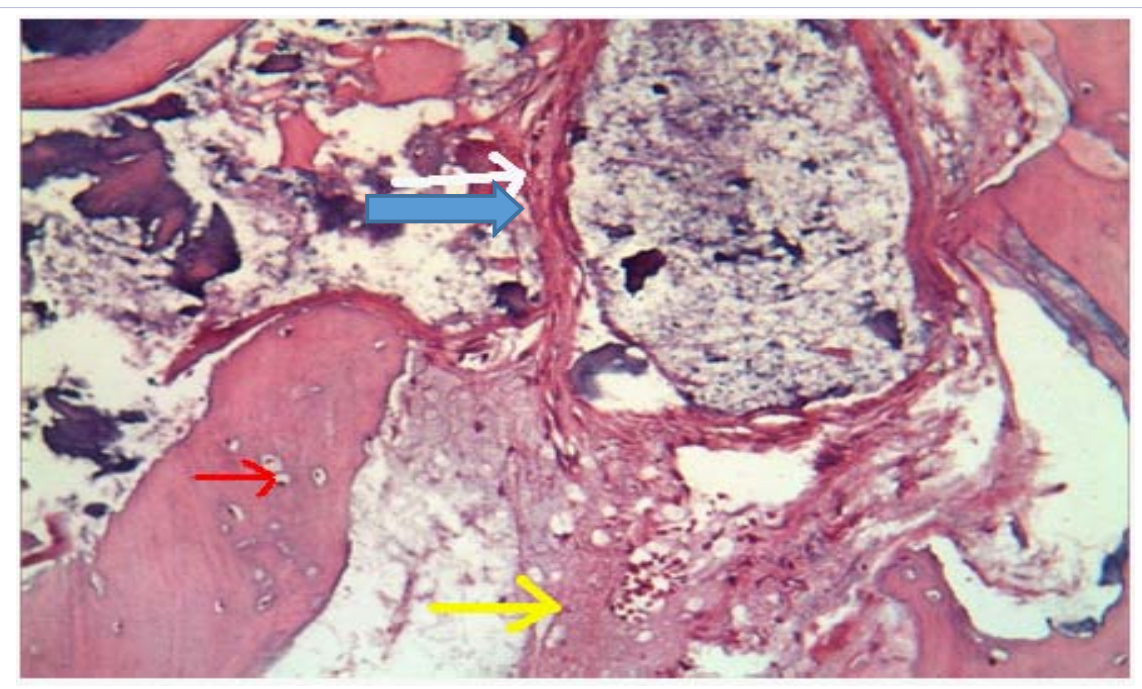

Figure 8: A photomicrograph of living woven bone tissue showing lacunae containing viable osteocytes (red arrow). Another area shows beginning of woven bone formation (area of hyalinized tissue around osteocytes) (yellow arrow). Another area shows condensation of collagen fibers around an area of dystrophic calcification (blue arrow) (H\&E 200X). 


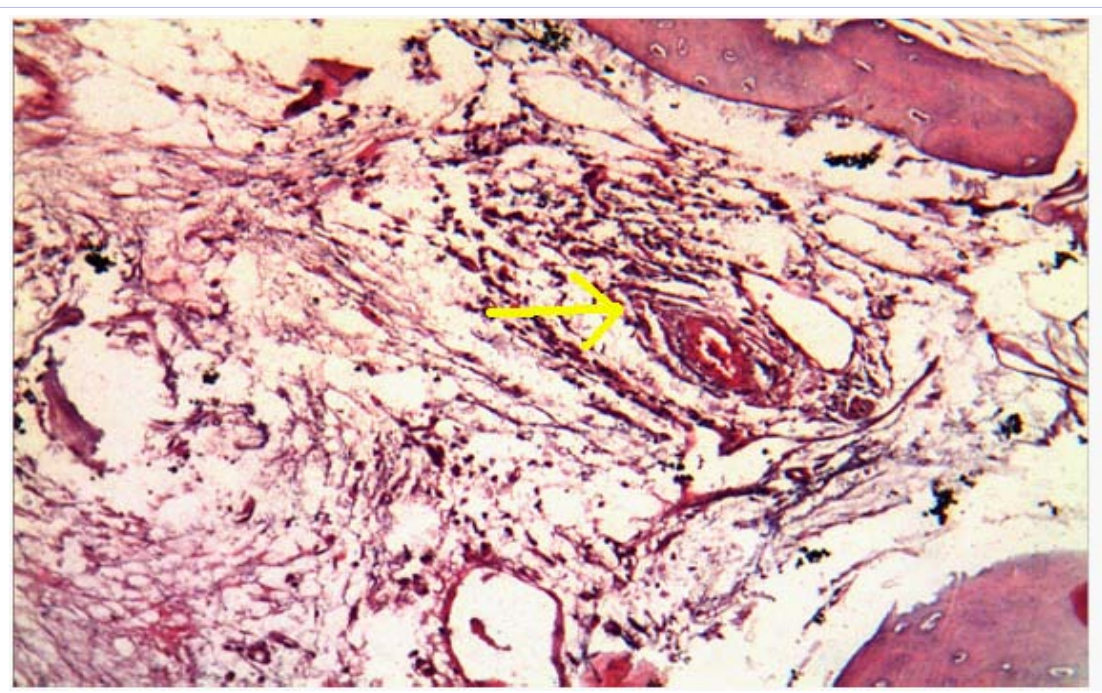

Figure 9: Higher magnification of the previous photomicrograph showing inflammatory cell infiltration around an area of hemorrhage (yellow arrow) (H\&E 200X).

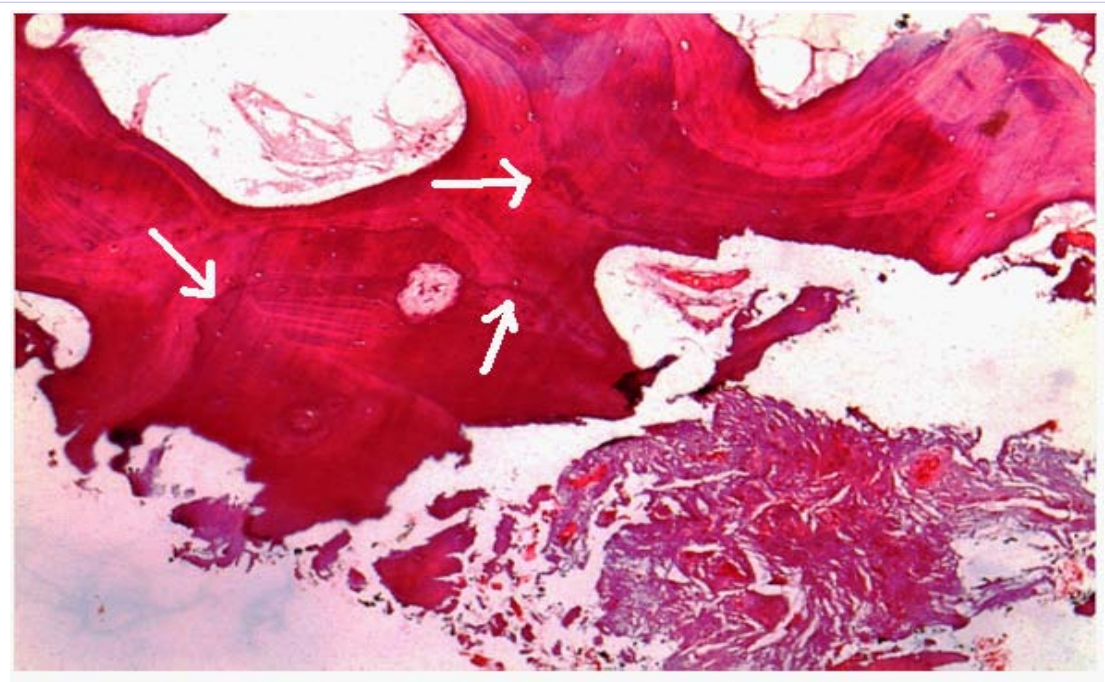

Figure 10: Photomicrograph of dense woven bone tissue showing some reversal lines denoting bone resorption followed by bone formation (white arrows) surrounded by disorganized connective tissue stroma (H\&E 200X).

shown, a greater amount of newly formed bone close to the residual crest (natural bone) compared with the amount in the whole biopsy sample. This is because the healing and maturation of the graft is derived from the cellular and vascular supply of the residual maxillary bone [22].

The histological findings supported the idea that porcine bone had good biocompatibility and excellent osteoconductive properties. Histological results indicated that both osteogenesis and angiogenesis followed ordinary periods; moreover, osteoblasts were observed apposing osteoid matrix directly on graft particles. In addition, the presence of multinucleated cells in resorption lacunae along the surface of porcine bone particles and the presence of bone metabolizing units within granules indicated that a remodeling/resorption processes were taking place. This agree with the result of bone density obtained from the six months postoperative CBCTs, which indicated the increase in the bone density. This is due to the presence of new bone formation $[23,24]$.

The clinical success observed with porcine bone depends on the surface topography of the graft material [25]. The macro and micro-porosity have a decisive role in osteoconduction, because both sufficient pore size and an interconnecting pore structure are required for osteoblast to grow into graft biomaterial [26]. Some authors observed that pores of $100-300 \mathrm{~mm}$ would be necessary for vascularization and osteoblast migration [27].

\section{Conclusion}

In conclusion, findings from the present study supported the hypothesis that collagenated porcine bone has excellent osteoconductive properties and can be partially reabsorbed. 
Moreover, the collagenated porcine bone allows an increase in the percentage of new bone and, at the same time, a reduction in the percentage of residual grafting material. This is very important because it is still under discussion whether the different biomaterials, such as bovine bone, will be reabsorbed with time.

However, more studies in which collagenated corticocancellous porcine bone is involved are needed before routine clinical use can be recommended.

\section{References}

1. Yamanichi N, Itose T, Neiva R,Wang HL. Long-term evaluation of implant survival in augmented sinuses: a case series. Int J Periodontics Restorative Dent. 2008; 28(2): 163-9.

2. Nannmark U, Sennerby L. The bone tissue responses to prehydrated and collagenated cortico-cancellous porcine bone grafts: a study in rabbit maxillary defects. Clin Implant Dent Relat Res. 2008; 10(4) 264-70. doi: 10.1111/j.1708-8208.2007.00080.x.

3. Valentini P, Abensur D. Maxillary sinus floor elevation for implant placement with demineralized freeze-dried bone and bovine bone (Bio-Oss $囚$ ): a clinical study of 20 patients. Int J Periodontics Restorative Dent. 1997; 17(3): 233-241.

4. Valentini P, Abensur D, Densari D, Graziani JN, Hammerle CF. Histological evaluations of Bio-Oss $®$ in a 2-stage sinus floor elevation and implantation procedure. A human case report. Clin Oral Implants Res. 1998; 9(1): 59-64.

5. Valentini P, Abensur D, Wenz B, Peetz M, Schenk R. Sinus grafting with porous bone mineral (Bio-Oss $®$ ) for implant placement: a 5 year study on 15 patients. Int J Periodontics Restorative Dent. 2000; 20(3) 245-53.

6. Piattelli M, Favero GF, Scarano A, Orsini G, Piattelli A. Bone reactions to anorganic bovine bone (Bio-Oss) used in sinus lifting procedure: a histologic long-term report of 20 cases in man. Int J Oral Maxillofac Implants. 1999; 14(6): 835-40.

7. Froum SJ, Tarnow DP, Wallace SS, Rohrer MD, Cho SC. Sinus floor elevation using anorganic bovine bone matrix (OsteoGraf/N) with and without autogenous bone: a clinical,histologic, radiographic, and histomorphometric analysis - part 2 of an ongoing prospective study. Int J Periodontics Restorative Dent. 1998; 18(6): 529-43.

8. Artzi Z, Nemcovsky CE, Dayan D. Bovine-HA spongiosa blocks and immediate implant placement in sinus augmentation procedures. Histopathological and histomorphometricobservations on different histological stainings in 10 consecutive patients. Clin Oral Implants Res. 2002; 13(4): 420-427.

9. Landi L, Pretel RW, Hakimi NM, Setayesh R. Maxillary sinus floor elevation using a combination of DFDBA and bovine derived porous hydroxyapatite: a preliminary histologic and histomorphometric report. Int J Periodontics Restorative Dent. 2000; 20(6): 575-83.

10. Scarano A, Degidi M, Iezzi G, Pecora G, Piattelli M, Orsini G, et al. Maxillary sinus augmentation with different biomaterials. A comparative histologic and histomorphometric study in man. Implant Dent. 2006; 15(2): 197-207.

11. Mangano C, Scarano A, Perrotti V, Iezzi G, Piattelli A. Maxillary sinus augmentation with a porous synthetic hydroxyapatite and bovine derived hydroxyapatite: comparativeclinical and histological study. Int J Oral Maxillofac Implants. 2007; 22(6): 980-6.
12. Wallace SS, Froum SJ. Effect of maxillary sinus augmentation on the survival of endosseous dental implants. A systematic review. Ann Periodontol. 2003; 8(1): 328-3.

13. Del Fabbro M, Testori T, Francetti L, Weinstein R. Systematic review of survival rates for implants placed in the grafted maxillary sinus. Int J Periodontics Restorative Dent. 2004; 24(6): 565-78.

14. Aghaloo TL, Moy PK. Which hard tissue augmentation techniques are the most successful in furnishing bony support for implant placement? Int J Oral Maxillofac Implants. 2007; 22: 49-70.

15. Figueiredo M, Henriques J, Martins G, Guerra F, Judas F, Figueiredo H. Physicochemical Characterization of Biomaterials Commonly Used In Dentistry As Bone Substitutes - Comparison With Human Bone J Biomed Mater Res B Appl Biomater. 2010; 92(2): 409-19. doi: 10.1002/jbm.b.31529.

16. Nannmark U, Sennerby L. The Bone Tissue Responses to Prehydrated And Collagenated Cortico-Cancellous Porcine Bone Grafts: A Study In Rabbit Maxillary Defects. Clin Implant Dent Relat Res. 2008;10(4):26470. doi: 10.1111/j.1708-8208.2007.00080.x.

17. Misch CE, Moore P. Steroids and the reduction of pain, edema and dysfunction in implant dentistry. Int J Oral Implantol. 1989; 6(1): 27-31.

18. Boyne PJ, James RA. Grafting of the maxillary sinus floor with autogenous marrow and bone. J Oral Surg. 1980; 38(8): 613-616.

19. Norton MR, Odell EW, Thompson ID, Cook RJ. Efficacy of bovine bone mineral for alveolar augmentation: a human histologic study. Clin Oral Implants Res. 2003; 14(6): 775- 783.

20. Misch CE. Divisions of available bone in implant dentistry. Int J Oral Implantol. 1990; 7(1): 9-17.

21. Hallman M, Sennerby L, Lundgren S. A clinical and histological evaluation of implant integration in the posterior maxilla after sinus floor augmentation with autogenous bone, bovine hydroxyapatite, or a 20:80 mixture. Int J Oral Maxillofac Implants. 2002; 17(5): 635-643.

22. Jakse N, Tangl S, Gilli R, Berghold A, Lorenzoni M, Eskici A, et al. Influence of PRP on autogenous sinus grafts. An experimental study on sheep. Clin Oral Implants Res. 2003; 14(5): 578 - 583.

23. Orsini G, Scarano A, Piattelli M, Piccirilli M, Caputi S, Piattelli A. Histologic and ultra-structural analysis of regenerated bone in maxillary sinus augmentation using a porcine bone derived biomaterial. J Periodontol. 2006; 77(12):1984-1990.

24. Dellavia C, Tartaglia G, Sforza C. Histomorphometric Analysis of Human Maxillary Sinus Lift with a New Bone Substitute Bioco mposite: A Preliminary Report. Clin Implant Dent Relat Res. 2009; 11 Suppl 1:59-68. doi: 10.1111/j.1708-8208.2009.00203.x.

25. Barone A, Santini S, Marconcini S, Giacomelli L, Gherlone E, Covani U. Osteotomy and membrane elevation during the maxillary sinus augmentation procedure. A comparative study: piezoelectric device vs. conventional rotative instruments. Clin Oral Implants Res. 2008; 19(5): 511-515. doi: 10.1111/j.1600-0501.2007.01498.x

26. Joschek S, Nies B, Krotz R, Göferich A. Chemical and physicochemical characterization of porous hydroxyapatite ceramics made of natural bone. Biomaterials. 2000; 21(16):1645-1658.

27. Schliephake H, Van den Berghe P, Neukam FW. Osseointegration of titanium fixtures in onlay grafting procedures with autogenous bone and hydroxyapatite.An experimental Histometric study. Clin Oral Implants Res. 1991; 2(2): 56-61. 